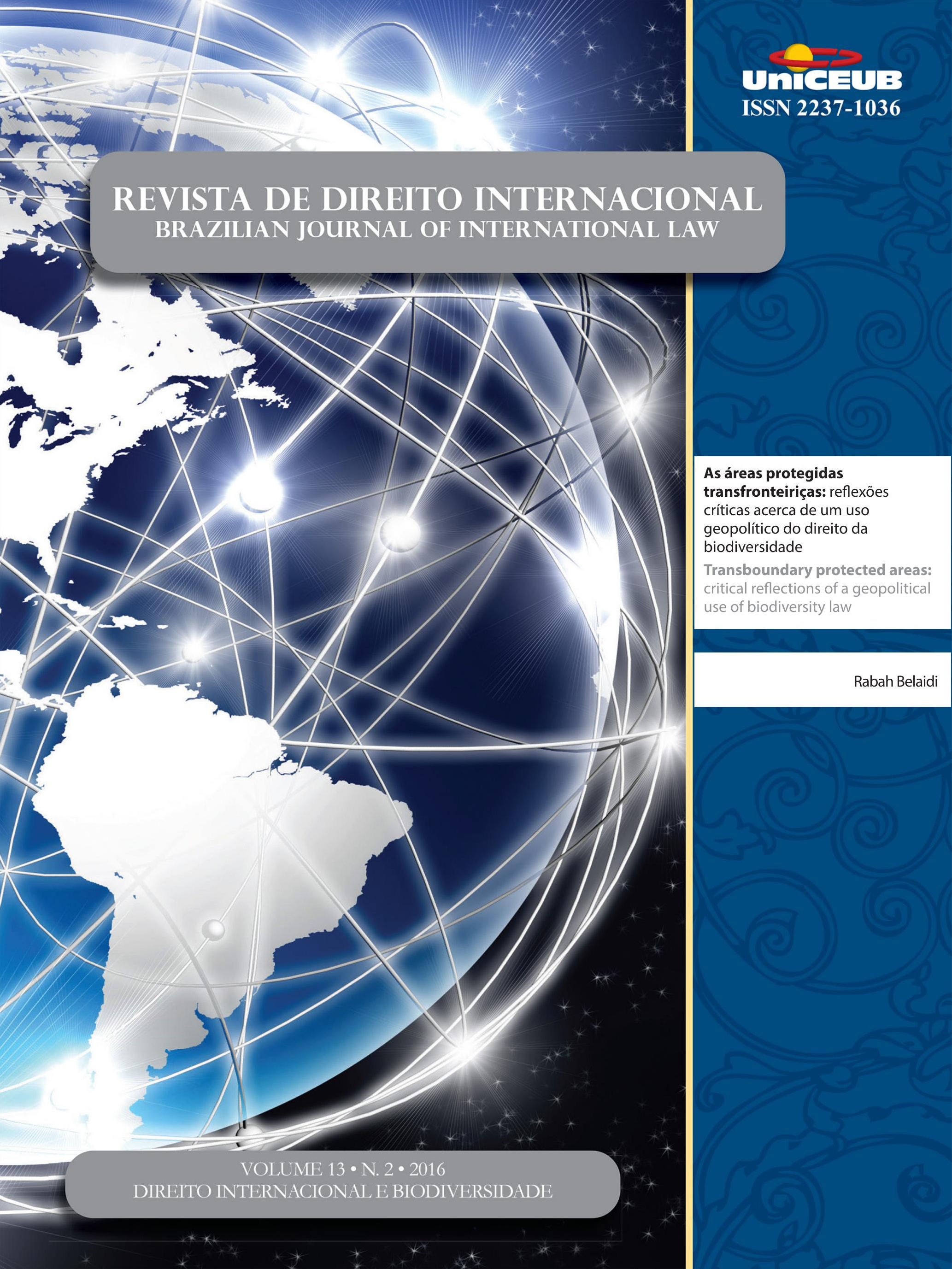




\section{Sumário}

CRÔNICAS DE DIREITO INTERNACIONAL PRIVADO 3 Gustavo Ferreira Ribeiro, Inez Lopes Matos Carneiro de Farias, Nadia de Araujo e Marcelo De Nardi

EDITORIAL 22

Márcia Dieguez Leuzinger e Solange Teles da Silva

IMPROVING THE EFFECTIVENESS OF LEGAL ARRANGEMENTS TO PROTECT BIODIVERSITY: AUSTRALIA AND BRAZIL .25

Paul Martin, Márcia Dieguez Leuzinger e Solange Teles da Silva

O RECONHECIMENTO DA DIGNIDADE DOS ELEMENTOS DA BIODIVERSIDADE COM BASE NO DIÁLOGO ENTRE O DIREITO INTERNACIONAL E O ORDENAMENTO JURÍDICO BRASILEIRO

Augusto César Leite de Resende

O REGIME INTERNACIONAL DO CLIMA E A PROTEÇÃO AOS “REFUgIADOS CLIMÁTICOS”: QUAIS DESAFIOS DA COP 21?

Ana Carolina Barbosa Pereira Matos e Tarin Cristino Frota Mont'Alverne

A anÁlise do MECANismo REdD+ COM Vistas À MitigaÇÃo dos EFEITOS DAS MUdANÇAS CLIMÁTICAS E À PROTEÇÃO DA DIVERSIDADE BIOLÓGICA FLORESTAL

Diogo Andreola Serraglio e Heline Sivini Ferreira

ECOLABELS DE EFICIÊNCIA ENERGÉtiCA E SUA CONSISTÊNCIA COM A DISCIPLINA DOS PPM's E PROVISÕES dOs Acordos GATT E TBT.

Cristiane Derani e Arthur Rodrigues Dalmarco

ANÁLISIS DEL ORDENAMIENTO JURÍDICO INTERNACIONAL SOBRE PROTECCIÓN DE LOS RECURSOS GENÉTICOS: DESAFIOS Y PERSPECTIVAS EN URUGUAY A PARTIR DE LA IMPLEMENTACIÓN DEL PROTOCOLO DE NAgOYA 115

Alina Celi 
LE RÉGIME INTERNATIONAL DE L'ACCÈS AUX RESSOURCES GÉNÉTIQUES AU PRISME DE L'ENTRÉE

en VIgUeUr du Protocole de NAgoya .............................................................. 131

Rodolpho Zahluth Bastos, Otávio Canto, Karine Galy e Isabelle Vestris

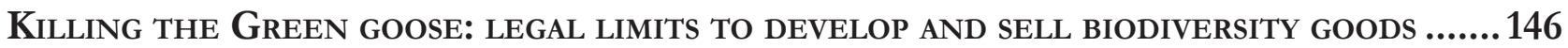
José Augusto Fontoura Costa e Liziane Paixão Silva Oliveira

VÍNCULO SUBSTANCIAL E AS BANDEIRAS DE CONVENIÊNCIA: CONSEQUÊNCIAS AMBIENTAIS DECORRENTES DOS NAVIOS COM REGISTROS ABERTOS ....................................................... 160

Marcos Edmar Ramos Alvares da Silva e André de Paiva Toledo

ANÁLISE DE CONTRATOS PÚblicos SOCIOAMBIENTAIS NO CENÁRIO PORTUGUÊS DE CRISE ECONÔ-

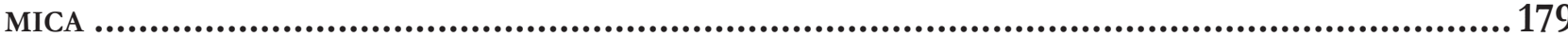

Alice Rocha da Silva e Matheus Passos Silva

A ORganizaÇão do TRATAdo DE COOPERAÇão AMAZÔNICA: UMA ANÁLISE CRÍTICA dAS RAZÕES POR TRÁS DA SUA CRIAÇÃO E EVOLUÇÃO

Paulo Henrique Faria Nunes

O uso de EXPERTS EM Controvérsias ambientais Perante a CorTe InTERnacional de JusTIÇA ........................................................................................................245

Lucas Carlos Lima

Os VIESES dA BIODIVERSIDAdE APRESENTAdos PELO CASO do PARQUE EÓlico DE BALd HiLls ......261 Natália Zampieri e Mariana Cabral

Mining CBD 275

Claire Lajaunie e Pierre Mazzega

Biotecnologia moderna, direito e o pensamento Abissal

Reichardt, F.V., Garavello, M. E. P. E., Molina, S.M.G. e Ballester, M. V. R.

Community Core Values como parâmetro de efetivação dos Princípios da Precaução e da Participação Popular em instrumentos de controle de projeto atividade de alta COMPLEXIDADE AMBIENTAL................................................................................... 314

Michelle Lucas Cardoso Balbino 
Discussões BIOTECNOLÓgICAS QUANTO AOS ORGANISMOS GENETICAMENTE MODIFICADOS NO ÂMBito da OMC: do contencioso ao acordo de vontades entre Argentina e União EuroPEIA

Gustavo Paschoal Oliveira

O Trans-Pacific Partnership Agreement e seus potenciais impactos para a regulação

DA BIODIVERSIDADE NO ÂMBITO TRANSNACIONAL..........................................................375

Mariana Yante Barrêto Pereira

AS ÁREAS PROTEGIDAS TRANSFRONTEIRIÇAS: REFLEXÕES CRÍTICAS ACERCA DE UM USO GEOPOLÍTICO DO DIREITO DA BIODIVERSIDADE.

Rabah Belaidi

O Que o caso Estados Unidos vs. Texas nos dirá sobre o direito de IMigração nos EsTADOS UNIDOS? 409

Danielle Anne Pamplona

Clóvis Beviláqua e a justiça internacional: entre o sim E o Não a Rui Barbosa.... .422 Paulo Emílio Vauthier Borges de Macedo

Possibilidade de delegação de atribuição para a Celebração de Tratados pela RepúbliCa Federativa do Brasil: análise do artigo 84, VIII c/c Parágrafo único da ConstituiÇão FEDERAL

Luciano Monti Favaro e Héctor Valverde Santana

Dignity, ubuntu, HUMANiTY AND AUTONOMOUS WEAPON SYSTEMS (AWS) DEBATE: AN AfRiCAN PERSPECTIVE 460

Thompson Chengeta

DiREITO INTERNACIONAL PRIVADO E O DIREITO TRANSNACIONAL: ENTRE A UNIFICAÇÃO E A ANARQUIA .503

André De Carvalho Ramos

A ilusória ausênCia do termo DépeÇage na JURisprudênCia brasileira de contratos INTERNACIONAIS

Gustavo Ferreira Ribeiro 
O EFEITO DIRETO DAS DIRETIVAS E OS DIREITOS FUNDAMENTAIS........................................535 Lucas Fonseca e Melo e José Levi Mello do Amaral Júnior

DA APLICABILIDADE DO BULK FACTORING AOS GRUPOS DE SOCIEDADES 565 Daniel Amin Ferraz e Leonardo Arêba Pinto

A Questão hermenêutica no direito das GENTES ................................................580 Inocêncio Mártires Coelho 


\title{
As áreas protegidas transfronteiriças: reflexões críticas acerca de um uso geopolítico do direito da biodiversidade*
}

\author{
Transboundary protected areas: critical \\ reflections of a geopolitical use of biodiversity \\ law
}

Rabah Belaidi**

\section{Resumo}

O objetivo deste trabalho visa esclarecer o regime das áreas protegidas transfronteiriças e mostrar que a produção de categorias heterogêneas, fragmentadas e complexas traz um emaranhado de dispositivos jurídicos oriundo de vários ordenamentos jurídicos que se sobrepõem e interagem em função dos territórios. O método usado é baseado na hipótese de que a biodiversidade forma um campo, no sentido dos conceitos do sociólogo Pierre Bourdieu. Permite verificar como alguns atores dotados de mais capital simbólico adquiriram posições dominantes e estruturam-se, juridicamente, nesse campo. Para além da descrição de um discurso dogmático-doutrinário, nossa contribuição examina, de forma crítica e a partir de uma análise territorial do direito, a utilização das categorias normativas em termos geopolíticos. O próprio regime criou suas subcategorias e orientou o foco em termos de funções pacificadoras dos territórios, notadamente na região da África austral. A pesquisa revela que os agentes envolvidos na implementação de áreas protegidas transfronteiriças orientam essa proteção numa função conservacionista da biodiversidade e aplicam uma política embasada em critérios de gestão e de cooperação. $\mathrm{O}$ trabalho desvela, no entanto, que os atores usam desse regime jurídico para conquistar posições dominantes em termos geopolíticos e que as consequências da proteção ofertada a alguns territórios os transformam em projetos eminentemente econômicos, levando a desalojar populações autóctones daqueles espaços remanejados. As limitações da pesquisa a algumas áreas, principalmente africana, permite abrir a problemática a outras regiões do mundo para que se verifiquem as implicações geopolíticas do uso das áreas protegidas transfronteiriças. $\mathrm{O}$ valor e a originalidade do trabalho residem não somente na exploração de um tema pouco estudado em direito internacional, mas também no emprego de uma abordagem geográfica do direito, especificamente nos seus aspectos geopolíticos.

Palavras-Chave: Áreas Protegidas Transfronteiriças. Direito Internacional. Biodiversidade. Geopolítica.

* Recebido em 02/05/2016

Aprovado em 07/06/2016

** Professor da Universidade Federal de Goiás (UFG). Mestre e Doutor da Universidade Panthéon-Assas (Paris 2).rbelaidi@gmail.com 


\section{Abstract}

The aim of this paper is to clarify the rules of the transboundary protected areas and show that the production of heterogeneous, fragmented and complex categories brings a tangle of legal devices come from various legal systems which overlap and interact in ter$\mathrm{ms}$ of territories. The method used is based on the hypothesis that biodiversity forms a field towards the concepts of sociologist Pierre Bourdieu. It's shows how some actors endowed with more symbolic capital acquired dominance and legal structure in this field. In addition to the description of a dogmatic legal discourse, our contribution examines, critically and from a territorial analysis of law, the use of normative categories in geopolitical terms. The regime itself has created its subcategories and directed the focus in terms of pacifying functions of the territories, especially in the Southern African region. Research reveals that the agents involved in the implementation of transboundary protected areas guide this protection a conservation function of biodiversity and apply an informed policy management and cooperation criteria. The work reveals, however, that the actors use this legal regime to gain dominant positions in geopolitical terms and that the consequences of offered protection to some territories, turn them into eminently economic projects leading to evict indigenous peoples of those relocated spaces. The limitations of the research to some areas, mainly African, opens the issue to other regions of the world to check the geopolitical implications of the use of cross-border protected areas. The value and originality of the work resides not only in the exploration of a little studied topic in international law, but in using a geographical approach to the law, specifically in its geopolitical aspects.

Keywords: Transboundary Protected Area. International Public Law. Biodiversity. Geopolitics.

\section{INTRODUÇÃO}

Se a ideia de proteção jurídica de áreas da natureza já apresenta mais de um século de atuação em alguns países, por outro lado, pouco se discute em direito internacional a pertinência, a complexidade, as contradições ou o uso social e político das aéreas protegidas transfronteiricas (APTF). Em Língua Portuguesa, os raros escritos sobre a matéria são, geralmente, estudos produzidos por geógrafos ou especialistas em ecologia, ciências ambientais e florestais ${ }^{1}$.

A publicação, em 1980, da estratégia mundial para a conservação revelou um objetivo novo do futuro marco regulatório das políticas internacionais de meio ambiente. Fruto do trabalho da União Internacional para a Conservação da Natureza (UICN), do Fundo Mundial para a Natureza (World Wide Fund/WWF) e do Programa das Nações Unidas para o Meio Ambiente, essa estratégia é vista como uma ruptura do discurso e dos elementos de linguagem das ONG's que atuam no campo da biodiversidade e da proteção da natureza. A conferência do Rio de 1992 consagrou as ONG's como interlocutores de importância das agências onusianas e de outras organizações internacionais de fomento.

Em nome de objetivos tais como biodiversidade, conservação ambiental, segurança alimentar e desenvolvimento sustentável, um grupo diversificado de atores públicos, privados e transnacionais atuam de forma a recompor alguns territórios do Sul. Essas estratégias de reconfiguração espacial podem ter um impacto sobre o acesso aos recursos naturais, seu controle ou sua gestão ${ }^{2}$.

A necessidade da conservação ambiental constitui uma das questões mais importante do discurso normativo do atores do campo da biodiversidade ${ }^{3}$. As diferenças podem ser notadas nas dimensões e modalidades da proteção, que se traduzem pela alternativa: conservacionista/preservacionista. Os conservacionistas enxergam a conservação, não como finalidade, mas sim como um meio para a realizado de outros objetivos tais que a segurança alimentar, a exemplo da FAO, o lucro para as empresas que podem apropriar-se da retórica da biodiversidade em supostas ações de responsabilidade ética, social e ambiental. Os conservacionistas juntam várias organizações dedicadas a proteção da natureza, próximas dos estados, a exemplo do World Wild Fund for Nature (WWF), Birdlife, Conservation Internatio-

1 STEIMAN, Rebeca. Áreas protegidas em zona de fronteira. Para Onde!?, v. 5, p. 101-121, ago.-dez. 2011. (Especial). KROPF, Marcela Stuker; OLIVEIRA, Rogério Ribeiro. Áreas protegidas fronteiriças. Revista Perspectiva Geográfica, Unioeste, v. 8, n. 9, 2013.

2 BASSET, Thomas J.; GAUTIER Denis. Territorialisation et pouvoir : la Political Ecology des territoires de conservation et de développement. Echo Géo, v. 29, 2014.

3 Excluindo as empresas e as populações locais envolvidas em conflitos ou litígios. 
nal, Fauna and Flora International, que assumiram um papel importante na preparação técnica da Convenção da Diversidade Biológica de 1992 (CDB). O desempenho dessas organizações não se limita a $\mathrm{CDB}$, mas sim continua, de forma perene, participando ativamente das Conferências das Partes da CDB (COP) zelando para o bom funcionamento da convenção. Assim, a COP 7 de Marraquexe foi um marco importante para as áreas protegidas, notadamente por meio da decisão VII/28 que reflete, na verdade, o fruto do trabalho e da experiência das principais organizações internacionais que estruturam o campo da biodiversidade. Por outro lado, os preservacionistas tais como a UNESCO, e de certa forma $\mathrm{UICN}^{4}$, enxergam a proteção da natureza e do meio ambiente como uma finalidade, sem que haja possibilidades de uso dos recursos da biodiversidade. Elabora-se uma trama complexa de relações de poder no campo da biodiversidade entre diversos atores privados, sobretudo organizações internacionais não governamentais, associadas ou não a organizações governamentais. Para alguns autores, uma terceira corrente, chamada de desenvolvimentista, nasceu da crítica do conservacionismo considerado como demasiadamente próximo de um uso liberal da natureza e da biodiversidade. Essa corrente pretende ocupar um espaço no meio e assume uma posição menos radical que os preservacionistas, sendo favorável a um uso sustentável da natureza. Essas construções de abordagens teóricas e práticas de proteção da natureza constituem o pano de fundo atual da governança da biodiversidade ${ }^{5}$ e, consequentemente, do posicionamento das organizações que regulam as APTF.

Os parques nacionais, reservas de biosfera e parques da paz são exemplos bem conhecidos de práticas territoriais estatais numa perspectiva de governança pela conservação e o desenvolvimento. $\mathrm{O}$ fenômeno novo que foi identificado, nesses últimos anos, pelos geógrafos é a proliferação de atores diversos, de práticas e de normas heterogêneas na territorialização de alguns

4 A partir de 1972, a UICN assume uma mudança progressiva para uma identidade conservacionista desenvolvimentista.

5 Para uma apresentação descritiva detalhada e interpretativa do cenário da governança da biodiversidade, a contribuição do Institut du Développment Durable et des Relations Internacionales (IDDRI) faz-se pertinente: BRAHI, Nicolas; LOUAFI, Sélim. La convention sur la diversité biologique à la croisée de quatre discours. Les Rapports de l'IDDRI, n. 3, p. 32, 2004. Para uma apresentação diferente e divergente: HUFTY, Marc. La gouvernance internationale de la biodiversité, Etudes internationales, v. 32, n. 1, p. 5-29, mars 2001. espaços ${ }^{6}$. Uma dessas práticas de remanejamento territorial é denominada de áreas protegidas transfronteiriças. O presente artigo apresentará, de forma sintética, o "regime" dessas áreas, alimentado por uma profusão de atores, que cria uma situação cuja arquitetura normativa é complexa e fragmentada (1). É possível desvelar, a partir de uma análise geopolítica, alguns dos interesses que levam esses atores a implementar essas áreas (2).

\section{O REGIME JURÍDICO DAS APTF: ENTRE DIVERSIDADE DE ATORES E HETEOGENEIDADE NORMATIVA}

Formulamos, presentemente, a hipótese de que a biodiversidade forma um campo no sentido da sociologia de Pierre Bourdieu dentro do qual os atores normativos que o compõem apresentam uma identidade singular, não homogênea que reflete as posições, interesses e recursos específicos a esse campo (1.1). Assim, essa pluralidade de regimes jurídicos das APTF mostra que os atores normativos são diversos e plurais quanto a sua natureza jurídica, ao passo que a produção de categorias de proteção jurídica mostra-se heterogênea (1.2).

\subsection{O campo da biodiversidade : abordagem teórica}

Adotando uma concepção bourdivina ${ }^{7}$, a biodiversidade pode ser entendida como um campo social, ou seja como "um espaço social estruturado em torno de interesses comuns e compostos de atores, de possibilidades, de referências comuns, de leis e de procedimentos". Para Bourdieu, a concorrência é a principal característica da interação que identifica o conjunto dos cam-

6 Fairhead J. Apud BASSET, Thomas J.; GAUTIER Denis. Territorialisation et pouvoir : la Political Ecology des territoires de conservation et de développement. Echo Géo, v. 29, 2014.

7 De Pierre Bourdieu, sociólogo francês, 1930-2002. Apesar de não ter dedicado parte importante de suas obras ao Direito, Bourdieu o investiga indiretamente por meio de pesquisas que tratam do Estado, do discurso do poder, enquanto seus seguidores aprofundam o tema das profissões judiciárias. No campo das Relações Internacionais, uma tendência a usar os conceitos de Pierre Bourdieu iniciouse, nessa última década, no Canadá, na Inglaterra, na Dinamarca, assim como, mas de forma mais discreta, na França. Pretendemos, de maneira compartimentada, aderir a esse quadro analítico no que tange a alguns aspectos do presente artigo.

8 BOURDIEU, Pierre. Questions de sociologie. Paris : Les Éditions de Minuit, 1984. p. 113. Tradução nossa. 
pos sociais. Os atores participando de um campo estão competindo para assumir o controle dos recursos criados pelo campo: os bens materiais ou as rendas que constituem o capital econômico, os conhecimentos científicos ou técnicos que definem parcialmente o capital cultural, as redes e as instituições que formam o capital social, assim como o prestígio associado ao domínio de outros valores ou códigos de conduta como o capital cultural. Dessa forma, esses atores atuam em um cenário que mobiliza regras específicas ao campo, que regulam a concorrência para o controle dos recursos e de suas possibilidades. Aliás, são justamente essas possibilidades, perspectivas e desafios que definem o campo. Assim, dentro do campo, os atores ocupam posições desiguais e competem entre dominantes e dominados para reverter esse quadro ou modificá-lo. A produção de normas e regras torna-se uma característica, assim como uma preocupação dos atores dominantes do campo que conseguem, consequentemente, definir o legítimo do ilegítimo sem verificação dos postulados de bases que embasam essa dominação. Essa última, além de traduzir-se por conceitos, ideias, normas e regras precisa também de meios para a circulação desses, fazendo do domínio da informação um dispositivo importante do controle de posição no campo. Para Bourdieu, esse agenciamento funciona e pode ser entendido com a ajuda de conceitos tais como "habitus", "senso prático", "violência simbólica". Assim, os atores procedem, inconscientemente, a um fenômeno de interiorização de suas posições no campo por meio de ações e percepções. Trata-se de uma ideia central de Bourdieu em razão das consequências, pois os atores investidos no campo desenvolvem estruturas mentais que correspondem a estruturas do campo. Esse processo de compreensão e de incorporação dos recursos e das regras do campo transforma, também, o ator mentalmente e corporalmente. Quando esse processo de incorporação termina, há uma correspondência imediata entre estruturas objetivas e disposições mentais dos atores. Consequentemente, o ator é incapaz de sair do "jogo", de observar a partir de um ponto de vista externo ou de poder compreender essa correspondência, essa "cumplicidade ontológica"9.

O conceito de habitus nada mais é do que a correspondência entre a estrutura mental e a estrutura objetiva do campo, ele é esse senso prático que permite o

9 BOURDIEU, Pierre. Raisons pratiques. Sur la théorie de l'action. Paris: Points Essais, 1996. p. 151. "domínio prático da lógica imanente" de cada campo. São as estruturas cognitivas que conseguem nos ajudar a entender o nosso papel no campo. Ademais, o mais importante, consiste em entender que as estruturas cognitivas não são faculdades inerentes ao gênero humano, assim como concebe Kant, mas sim uma disposição formada pelas estruturas objetivas de cada campo ${ }^{10}$. Segundo Bourdieu, há uma correspondência imediata entre as estruturas mentais, entre as disposições dos atores e a distribuição dos recursos disponíveis no campo. À medida que um ator for mais dotado de um habitus em adequação com as regras internas do campo, mais ele será dotado de capital específico desse campo, mais ele será capaz de perceber as possibilidades e os recursos do campo e mais ele será capaz de apropriar-se para ocupar as posições dominantes do campo.

No caso da biodiversidade, aquilo que está em jogo não é exatamente delimitado e oscila entre práticas e ideologias, a partir dos habitus e dos capitais simbólicos. Assim, a doutrina jurídica e aquela de ciência social divergem quanto aos critérios de identificação do campo da biodiversidade. Para Marc Hufty e Dominique Botti, que inspiraram nossa abordagem do tema, o campo da biodiversidade apresenta dois elementos chaves: a conservação e a apropriação, enquanto, para Albane Geslin, a alternativa deve ser enxergada entre preservação e conservação ${ }^{11 .}$

Antes de proceder ao estudo dessas divergências que podem mascarar um conflito político subjacente ${ }^{12}$, é preciso se ater a uma apresentação relativamente dogmática, técnica e descritiva dos diversos atores jurídicos do campo da biodiversidade e, especificamente, daqueles que operam com as áreas protegidas transfronteiriças $^{13}$.

10 LAHIRE, Bernard. La nature du cognitif en questions. In: LAHIRE, Bernard; ROSENTAL, Claude (Org.). La cognition au prisme des sciences sociales. Paris: Editions des archives contemporaines, 2008. p. 58.

11 HUFTY, Marc. La gouvernance internationale de la biodiversité, Etudes internationales, v. 32, n. 1, p. 5-29, mars 2001. BOTTI Dominique. La biodiversité comme champ de lutte: La Convention sur la diversité biologique et la réglementation international. Genève: Mémoire de DES, IUED, 1997.

GESLIN, Albane. Aires protégées transfrontalières et parcs pour la paix : entre géopolitique des conflits et protection transnationale de la diversité bio-culturelle. In: AILINCA Mihaela; LAVOREL Sabine. (Org.). Exploitation des ressources naturelles et protection des droits de l'homme. Paris: Éd. Pedone, 2013. p. 105-120.

12 Que será objeto da segunda parte do presente artigo.

13 Sabendo que a segunda parte do artigo terá uma dimensão mais teórica, no sentido de ultrapassar o simples discurso dogmático- 


\subsection{Uma profusão de atores e uma heterogeneidade normativa}

Apresentar os atores que compõem o campo da biodiversidade consiste em se deparar com uma forte e nítida diversidade, que traz o dilema do eixo a ser escolhido para tal apresentação. Existem, na verdade, várias possibilidades de delinear as categorias de atores. Cada discriminação traz consigo seus objetivos, seu modo de ver, assim como o enfoque da orientação, de forma a revelar tais ou tais aspectos em virtude de tais ou tais hipóteses.

Como classificar? Eis a questão. Poderíamos tocar no cerne da questão e desenvolver de antemão a relação complexa que existe entre as categorias de conservacionismo, preservacionismo, utilitarismo e recursismo, a fim de descrever a trama do discurso da biodiversidade. No entanto, como já foi explicado anteriormente, deixaremos essa opção para a segunda parte do artigo, momento no qual trataremos do uso geopolítico do direito. Assim, fizemos a escolha de apresentar a diversidade dos atores de forma mais técnica, diante da presença de múltiplos atores vindos de horizontes diferentes.

Optamos por uma apresentação do tipo macrojurídico para conseguir uma visão geral da diversidade dos atores da biodiversidade ${ }^{14}$. Segundo alguns teóricos e operadores da governança internacional do desenvolvimento sustentável, pode considerar-se quatro tipos de atores, instituições que interagem a partir de quatro regimes com legitimidades diferenciadas: a negociação institucional entre Estados, as organizações internacionais governamentais que administram e que executam as políticas, as redes de influências de empresas e de organizações internacionais não governamentais e, finalmente, os processos de expertise científica ${ }^{15}$.

doutrinário, a fim de desvelar os interesses que se permeiam por trás das formalidades do discurso formulado pelos atores da biodiversidade

14 Inspirados nesse sentido pelos trabalhos de Benoit Frydman da Université Libre de Bruxelles que adota uma abordagem macro e microjurídica para sair de um contexto de nacionalismo metodológico e poder abarcar de forma mais pertinente as problemáticas relacionadas ao estudo da globalização e do Direito.

CHÉROT, Jean-Yves ; FRYDMAN, Benoît (Org.). La science du droit dans la globalisation. Bruxelles: Bruylant, 2012. (coll. « Penser le droit $\gg)$.

15 BRODHAG, Christian. Quelle gouvernance internationale du développement durable. In: PENNEQUIN, Gilles; MOCILNIKAR, Antoine-Tristan (Org.). L'Atlas du développement durable. Paris: d'Organisation. Eyrolles, 2011. p.199.
Sem dúvida, esse esquema apresenta algumas insuficiências e imprecisões, notadamente de ordem jurídica. Com efeito, no que tange ao presente tema de estudo, o papel de algumas ONG's é, na verdade, central na proteção de áreas protegidas transfronteiriças, que podem ser pertinentemente incluídas no rol do desenvolvimento sustentável.

Esse presente estudo não se propõe a suprir as deficiências, faltas ou falhas do regime institucional de produção de normas e de administração das áreas protegidas transfronteiriças. Apresentaremos um breve panorama macro institucional que tem por objetivo enfatizar a extrema diversidade dos atores em jogo que obviamente não pretenderá a exaustividade.

\subsubsection{A União Internacional de Conservação da Natureza (UICN)}

Cabe destacar, em primeiro lugar, o papel central assumido pela União Internacional de Conservação da Natureza (UICN) na produção de normas acerca das áreas protegidas transfronteiriças. Criada em 1948, com a denominação de União Internacional para a Proteção da Natureza (UIPN), ela é a mais antiga ONG dedicada ao meio ambiente. A mudança de nome ocorre em 1956 par tornar-se a União Internacional para a Conservação da Natureza e dos Recursos Naturais (UICN ou IUCN em língua inglesa).

Ela possui uma estrutura bastante original, apesar do longo tempo de existência, pois agrega a participação de membros estatais e não governamentais, assegurando a eles o um direito de voto igual nas assembleias. Ela pode ser aproximada, com toda proporção, do regime jurídico-politico da Cruz Vermelha, embora não tenha capacidade jurídica de direito internacional público e portanto de participar da conclusão de tratados. Esse caráter sui generis que essas duas ONG's possuem explica, sem dúvida, o fato de ter sido escolhida pela ONU como ONG's que tem o estatuto de observadores. A UICN tornou-se um interlocutor privilegiado no cenário internacional das negociações sobre o meio ambiente e possui uma posição dominante no campo da biodiversidade, sendo "terceirizada" por inúmeros estados ou organizações internacionais a fim de iniciar, fomentar, redigir, negociar e ou consolidar a construção ou aplicação de convenções internacionais ${ }^{16}$. A missão

16 Juliette Olivier listou, de forma não exaustiva, un número im- 
da UICN consiste em influenciar, encorajar e ajudar as sociedades a conservar a integridade e a diversidade da natureza e de assegurar que os recursos naturais sejam usados de uma maneira equitável e sustentável. Com o seu programa sobre as Áreas Protegidas, a UICN está envolvida na gestão, no planejamento e no investimento de áreas protegidas. Com efeito, esse programa gerencia a Comissão Mundial das Áreas Protegidas (CAMP) que constitui a instituição de referência mundial das áreas protegidas em matéria de influência e de ação. A CMAP tem por objetivo promover e gerenciar de maneira eficaz uma rede mundial representativa de áreas protegidas (o Global Transboundary Protected Areas Network) ${ }^{17}$.

presionante de grandes convenções de meio ambiente que foram elaboradas com a presença da UICN: Convention africaine sur la convention de la nature, Alger, 15 septembre 1968 ; Convention relative aux zones humides d'importance internationale, Ramsar 2 février 1971 Convention sur la protection du patrimoine mondial culturel et naturel, UNESCO, Paris, 16 novembre 1972 (Convention du patrimoine mondial) Convention sur le commerce international des espèces de faune et de flore sauvages menacées d'extinction (CITES), Washington, 3 mars 1973 Accord relatif à la conservation des ours blancs, Oslo, 15 novembre 1973 Convention sur la conservation de la nature dans le Pacifique Sud, Apia, 12 juin 1976 Convention sur la conservation des espèces migratrices appartenant à la faune sauvage, Bonn, 23 juin 1979 Accord sur la conservation de la nature et des ressources naturelles, Kuala Lumpur, 9 juillet 1985 Convention sur la diversité biologique, Rio, 5 juin 1992 Accord sur la conservation des petits cétacés de la mer Baltique et de la mer du Nord, New York, 17 mars 1992 Accord sur la conservation des oiseaux d'eau migrateurs d'Afrique-Eurasie (AEWA), La Haye, 16 juin 1995 Accord sur la conservation des cétacés de la mer Noire, Méditerranée et de zone atlantique adjacente, Monaco, 24 novembre 1996 Convention internationale sur la responsabilité et l'indemnisation pour les dommages liés au transport en mer de substances nocives et potentiellement dangereuses, Londres, 3 mai 1996 Convention sur l'accès à l'information, la participation du public et l'accès à la justice en matière d'environnement, Aarhus, 25 juin 1998. OLIVIER, Juliette. Les nouveaux acteurs du droit de l'environnement. Le rôle de l'UICN dans l'élaboration du droit de l'environnement. Revue Européenne de Droit de l'Environnement, n. 3, p. 274-296, 2005.

17 É preciso mencionar o papel dos congressos mundiais de parques nacionais organizados pela UICN, que são reunidos uma vez por década, e conseguem agregar especialistas de várias disciplinas engajados na proteção da natureza e da biodiversidade por meio de gerenciamento de parques nacionais ou transfronteiriços. Aconteceram em: Seattle em 1962 para definição das normas das redes representativas, chegando à elaboração da Lista das Nações Unidas das áreas protegidas; Yellowstone em 1972 para tratar da conservação dos ecossistemas, da gênese da Convenção sobre o patrimônio mundial e da Convenção relativa as zonas húmidas; em Bali em 1982 para discutir das áreas protegidas e do desenvolvimento sustentável, das políticas de fomento ao desenvolvimento (aide an développement) nas áreas protegidas; em Caracas em 1992 para tratar das mudanças climáticas mundiais e das áreas protegidas, das categorias de áreas protegidas e da eficácia da gestão; em Durbam em 2003 para trabalhar sobre a governança, o financiamento sustentável, o reforço das capacidades, as relações entre paisagens terrestres
Para a UICN, as áreas protegidas podem ser definidas como espaços geográficos claramente definidos, reconhecidos, dedicados e gerenciados por meios legais ou outros, com a finalidade de favorecer a conservação em longo prazo da natureza e dos serviços ecossistêmicos e dos seus valores culturais ${ }^{18}$. É possível falar de área protegida transfronteiriça quando o espaço geográfico protege e agrega uma continuidade de aéreas protegidas dos lados das fronteiras de vários estados.

As seis categorias de gestão das áreas protegidas previstas pela $\mathrm{UICN}^{19}$ :

1. a Reserva natural integral: conservar os ecossistemas excepcionais em nível regional, nacional ou mundial, as espécies (individuais ou em grupos) e/ou as características da geodiversidade.

b Área de natureza selvagem: Proteger em longo prazo a integridade ecológica de áreas naturais que não foram modificadas pelas importantes atividades humanas.

2. Parque nacional: Proteger a biodiversidade natural, assim como a estrutura ecológica e os processos ambientais subjacentes, promover a educação e os lazeres.

3. Monumento ou elemento natural: Proteger os elementos naturais excepcionais específicos, assim como a biodiversidade e os habitats associados.

4. Áreas de gestão e de ordenamento dos habitats/ espécies : áreas protegidas que são gerenciadas num objetivo de conservação por meio de intervenções ativas.

5. Paisagem terrestre ou marinho protegido: Proteger e manter importantes paisagens terrestres ou mari-

e marinhos, a equidade e o a divisão dos benefícios; em Sidney em 2014 para tratar dos meios marinhos, do patrimônio mundial, do reforço das capacidades e do novo pacto mundial.

UICN. L'Histoire. 2014. Disponível em: < http://cmsdata.iucn.org/ downloads/fre_who_we_are_iucn_congress_history.pdf $>$. Acesso em: 3 abr. 2016.

Um dos raros trabalhos acadêmico disponível em língua portuguesa é de SOUZA, João Victor Campos de. Congressos Mundiais de Parques Nacionais da UICN (1962-2003): registros e reflexões sobre o surgimento de um novo paradigma para a conservação da natureza. 2013. 225 f. Dissertação (Mestrado) - Programa de Pós-Graduação em Desenvolvimento Sustentável, Universidade de Brasília, Brasília, 2013.

18 UICN. [Homepage]. Disponível em: <https://www.iucn.org/ $\mathrm{fr} /$ propos/travail/programmes/aires_protegees/>. Acesso em: 24 mar. 2016. Tradução nossa.

19 DUDLEY, Nigel. Lignes directrices pour l'application des catégories de gestion aux aires protégées. 2008. Disponível em: <https://portals. iucn.org/library/efiles/edocs/PAPS-016-Fr.pdf>. Acesso em: 24 mar. 2016. 
nhos, a conservação da natureza presente, assim como outros valores criados pelas interações com os homens e suas práticas de gestão tradicionais.

6. Área protegida com uma utilização sustentável dos recursos naturais: Proteger os ecossistemas naturais e utilizar os recursos naturais de forma sustentável, quando conservação e utilização sustentável podem ser mutualmente benéficos.

\subsubsection{A "Peace Parks Foundation" (Fundação dos Parques da Paz) ${ }^{20}$.}

A ONG Fundo Mundial pela Natureza (WWF) junto com o apoio da UICN criou, em 1997, a Peace Parks Foundation (Fundação dos Parques da Paz) no intuito de propor um suporte político, técnico, científico e financeiro aos projetos de APTF. Essa fundação que nasceu na África do Sul com o apoio de Nelson Mandela ${ }^{21}$ concentra principalmente suas ações na África austral, onde apoia 14 APTF (Peace Parks Foundation, 2011).

$\mathrm{Na}$ verdade, o conceito de parques da paz não é novo e pode ser datado a 1914 quando a Suécia e a Noruega criaram uma área protegida transfronteiriça para comemorar um século de paz entre ambos países. Essa iniciativa foi retomada pelos Estados-Unidos e o Canadá que criaram, em 1932, o primeiro parque internacional da paz ligando o Glaciário Nacional Parque americano com o parque nacional canadense Waterton Lakes. Na África, o conceito começou a aparecer na década de noventa quando as relações entre a África do Sul e os países vizinhos passaram por uma melhora com fim do apartheid em 1994. Desde 1997, a União internacional pela conservação da natureza (UICN) et a Peace Park Foundation, atuam no continente Africano e especificamente no sul da África. Assim, a África do Sul lidera o movimento, pois conta com seis parques, cujo mais famoso é o Great Limpopo Park entre Moçambique, Zimbábue e África do Sul. Em nível mundial, a UICN listou, até o presente momento, 169 parques da paz em 113 estados. Segundo Albane Geslin, o numero de APTF é difícil de ser estabelecido com uma grande

20 Categoria que será tratada de forma mais crítica no 2.2

21 Anton Rupert, ex-dirigente controvertido do WWF-África do Sul durante a apartheid, foi a origem dessa fundação que lança essa iniciativa no decorrer da reconciliação do povo sul africano protagonizada por Nelson Mandela. GUYOT, Sylvain. Géopolitique des parcs (trans) frontaliers en Afrique Australe. Les Cabiers d'Outre-Mer, v. 234, avril-juin 2006. precisão, tendo em vista que algumas áreas protegidas de estados vizinhos podem ser adjacentes sem que haja acordo de cooperação ou cooperação de fato entre eles $^{22}$. No entanto, o World Conservation Monitoring Centre do Programa das Nações Unidas para o Meio Ambiente estabeleceu uma lista mundial das ATPF em 2007 e identificou 227 áreas formando uma superfície de 4.6 milhões de $\mathrm{km} 2^{23}$. Os parques da paz são para a UICN, áreas transfronteiriças oficialmete dedicadas à proteção e manutenção da diversidade biológica e dos seus recursos naturais e culturais, assim como a promoção da paz e da cooperação.

\subsubsection{As reservas de Biosferas da UNESCO}

As reservas de Biosfera do programa MAB (Man and Biosphere) são dispositivos internacionais originais para implementar o desenvolvimento sustentável, que foram lançados pela UNESCO em 1970, dois anos depois da International conference on the scientific basis for rational use and conservation of the resources of the biosphere.

Seus objetivos foram definidos pela Conferência de Sevilla em 1995:

1. Conservação da diversidade biológica,

2) Promoção do desenvolvimento sustentável

3 Desenvolvimento das capacidades humanas e institucionais na apreensão das questões de meio ambiente.

Esse dispositivo apresenta-se como a implementação dos princípios da abordagem ecossistêmica da Convenção sobre a Diversidade Biológica em termos de escolhas de sociedade, do papel esperado do conhecimento científico e dos saberes locais, assim como da prática da subsidiariedade. As reservas inscrevem-se também no registro dos Millenium Development Goals e da conferência de Joanesburgo de 2002, para passar da retórica à ação para que se reduza significativamente a perda da biodiversidade.

22 GESLIN, Albane. Aires protégées transfrontalières et parcs pour la paix : entre géopolitique des conflits et protection transnationale de la diversité bio-culturelle. In: AILINCA Mihaela; LAVOREL Sabine. (Org.). Exploitation des ressources naturelles et protection des droits de l'homme. Paris: Éd. Pedone, 2013. p. 105-120.

23 SANDWITH, T. Transboundary Protected Area for Peace. and Co-operation. World Comission on Protected Áreas. Best Practice Protected Area Guidelines Series, n. 7, p. 3, 2001. Disponível em: $<$ https://cmsdata.iucn.org/downloads/pag_007.pdf $>$. Acesso em 12 abr. 2016. 
Elas devem combinar as funções de conservação da biodiversidade, de desenvolvimento local e de apoio logístico no seio de uma rede mundial. Elas se diferenciam de outros tipos de áreas destinadas principalmente ou exclusivamente à conservação. Essas especificidades decorrem da própria evolução das reservas de biosfera, que foram consolidadas em 1995 dentro do documento estatutário da rede mundial de 1996, que determina os princípios a serem implementados de forma adequada em relação ao tempo e ao espaço das reservas da biosfera. Em 2016, a rede mundial contabiliza 669 reservas de biosfera, incluindo 16 sítios transfronteiriças, em 120 países. A estratégia 2008-2015 do programa MAB da UNESCO visa:

a. desenvolver e reforçar os modelos de desenvolvimento sustentável dentro da rede mundial de reservas de biosfera;

b. compartilhar experiência e ensinos facilitando a difusão e a aplicação desses modelos em escala mundial;

c. apoiar a avaliação da gestão da qualidade, as estratégias e as políticas de desenvolvimento sustentável e de planificação, assim como as instituições responsáveis e resilientes;

d. ajudar os Estados-membros da Unesco e outras partes interessadas em atingir rapidamente os Objetivos do Desenvolvimento Sustentável apoiando-se na experiência da rede mundial de reservas da biosfera ${ }^{24}$.

\subsubsection{As Redes Europeias e Comunitárias}

O continente europeu ilustra, de forma manifesta, o emaranhado de dispositivos jurídicos em prol da conservação da natureza e proteção da biodiversidade. $\mathrm{O}$ sistema é complexo, pois apresenta uma série de instituições geradoras de normas de direito internacional regional, mas de origens diferentes, misturando interesses de bloco econômico, de organização internacional de direitos humanos e de atores transnacionais.

Assim, o Conselho da Europa foi precursor na institucionalização da conservação dos ecossistemas e da integração de paisagens, criando em 1976 a rede europeia das reservas biogenéticas ${ }^{25}$. Após a assinatura da

24 MAB FRANCE. Le MAB de l'UNESCO. Disponível em: $<$ http://www.mab-france.org/fr/mab-france/>. Acesso em: 10 abr. 2016. Tradução nossa.

25 O Conselho da Europa não deve ser confundido com uma
Convenção sobre a Biodiversidade de 1992, um agregado de instituições europeias lançou uma Estratégia pan-europeia para a proteção da diversidade biológica e de paisagens ${ }^{26}$. Uma Rede Ecológica Pan-europeia foi lançada para proteger a conservação dos ecossistemas, dos habitats, das espécies e das populações de espécies da zona pan-europeia, assim como que sua diversidade genética, por meio da conservação da integridade ecológica das paisagens de importância europeia. A elaboração complicada da rede não gerou os efeitos esperados e a estratégia, bastante criticada, foi reorientada. Nosso propósito não consiste na apresentação detalhada do sistema europeu, mas sim do símbolo que ele caracteriza por seus aspectos entrelaçados e complexos. A melhor forma de ilustrar esse aspecto consiste em mostrar, a partir de um estado europeu (a França) e de um quadro sintético, a diversidade de regimes de proteção.

O Quadro 1 revela, a partir do caso francês, a superposição e a complexidade de categorias normativas de proteção de origem, transnacional, internacional e européias.

Quadro 1: Participação da França as Convenções e Redes Internacionais de Áreas Protegidas

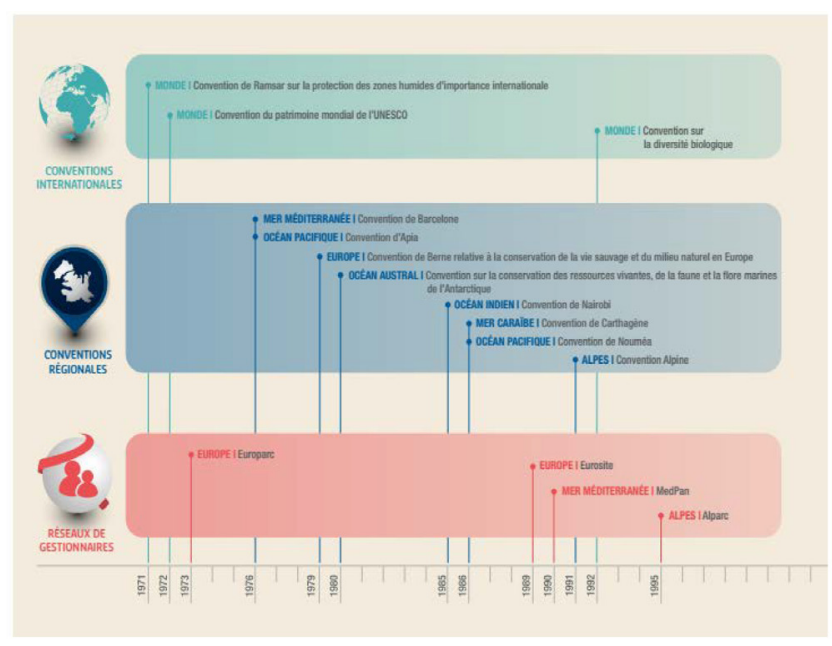

Fonte : UICN France (2013), Les espaces naturels protégés en France : une pluralité d'outils au service de la conservation de la biodiversité, Paris, p.15.

instituição da União Européia e especificamente com o Conselho Europeu. Trata-se de uma ONG que foi criada em 1949 pelo tratado de Londres para proteger os direitos humano, a democracia e a preeminência do direito no continente europeu. Agrega 47 estados membros e possui a personalidade jurídica internacional.

26 PEBLDS: Pan-European Biological and Landscape Diversity Strategy. 
Cabe mencionar que, ao lado das principais instituições supramencionadas que operam no âmbito das áreas protegidas transfronteiriças, há uma série de atores indiretos, mais discretos, que assumem um papel de apoio técnico, financeiro ou político e que reforçam a legitimidade das instituições primárias. Assim merecem ser citados, sem que tenhamos a pretensão de delinear o regime de suas participações, o Banco Mundial, a FAO, a União Europeia e União Econômica e Monetária do Oeste Africano.

Essa extrema diversidade de atores produz uma heterogeneidade de classificações e categorias de proteções jurídicas. A arquitetura jurídica das áreas protegidas transfronteiriças é, consequentemente, confusa e parece redundante, pois apresenta vários graus de escalas de atuação. Assim, é preciso distinguir a superposição de diferentes atores, oriundos de diferentes esferas jurídicas que propõem várias categorias jurídicas. Atores transnacionais, organizações internacionais não governamentais, organizações internacionais governamentais e estados. No entanto, a situação pode ser mais bem definida como um verdadeiro emaranhado, no sentido de que as categorias normativas propostas pelos diversos atores interagem permanentemente. Assim, em primeiro lugar, a criação de uma APTF pode agregar um acordo de direito internacional público entre dois o mais estados soberanos (e receber evidentemente a qualificação jurídica de tratado no sentido dos artigos 2 e 3 da Convenção de Viena de 1969). Mas, em segundo lugar, esse acordo é, na verdade, simultaneamente, o resultado e o suporte jurídico de uma norma anterior dentro de qual ele se encaixa (mesmo que de forma confusa ou imperfeita), oriunda dos padrões de uma organização não governamental (de direito privado) que produz um direito transnacional, a exemplo da IUCN. O quadro anterior $\left(\mathrm{n}^{\circ} 1\right)$ mostrou com muita clareza esse emaranhado; com efeito, a partir da visão de um território (neste caso o exemplo da França), é possível vislumbrar uma série de dispositivos jurídicos superpostos e entrecruzados, produzidos por uma série de atores de origens jurídicas diversas.

Sobre o questionamento acerca de qual seria o regime jurídico das APTF, a resposta é longa, complexa, esmiuçada, tendo em vista o esforço a ser feito para distinguir as configurações presentes no caso em espécie. Não é possível responder, de forma segura ou certa, afirmando que estaríamos necessariamente diante de um fenômeno de soft law, ou de outras qualidades normativas.

\section{O USO GEOPOLÍTICO DO REGIME DAS APTF: ENTRE CONSERVAÇÃO E PAZ}

A implementação de áreas protegidas, seja em contexto transfronteiriça ou nacional, sempre foi atravessada por um intenso e antigo debate sobre o conteúdo normativo e político das características de proteção. Não pretendemos, neste trabalho, investigar e dissertar a respeito. Cabe lembrar que, mesmo se os conceitos possam mudar de denominação, em virtude de autores ou de correntes científicas, há um certo consenso para apresentar as categorias em função do seu grau de proteção. Assim, em primeiro lugar, a concepção do preservacionismo se apresenta como a mais rigorosa por entender que a proteção das áreas deve ser total e não pode admitir circulação de pessoas humanas. Em segundo lugar, vem a política de conservação, que possibilita, mas, de maneira regulada, a circulação do ser humano na área protegida, notadamente por finalidade turística (não entendi muito bem a frase.

Se a lógica primeira das áreas protegidas tão nacionais quanto transfronteiriças foi de proteger a conservação da biodiversidade por meio de uma gestão e de ações de cooperação (3.1), surgiu na década de noventa um objetivo de paz, que além de ser isento de críticas de ordem geopolítica revela o funcionamento de lutas de posições no campo da biodiversidade por diversos atores (3.2).

\subsection{Um objetivo de gestão e de cooperação}

Os principais objetivos das APTF consistem na eliminação das barreiras a livre circulação da fauna, em melhorar o acesso ao turismo em estabelecer grupos de trabalho transfronteiriças apoiando a cooperação em longo prazo para a conservação da biodiversidade. Além disso, elas visam aumentar os benefícios da conservação e promover a distribuição dos benefícios com as partes associadas além das fronteiras, assim como facilitar as interações entre as comunidades envolvidas $^{27}$. Alguns objetivos específicos próprios aos parque

27 MONTPETIT, Sandrine. Les aires protégées transfrontalières: au-delà de la conservation de la biodiversité. 2013. 101f. Essai de maîtrise en écologie internationale. Faculté des Sciences, Université 
da paz foram igualmente mencionados por alguns observadores $^{28}$. Assim, o fato de incentivar a confiança, a compreensão, a reconciliação e a cooperação entre os atores, assim como promover a resolução de conflitos armados e a preservação da paz são outros requisitos. A conservação transfronteiriça inclui uma grande variedade de abordagens que têm em comum a ideia de estender as medidas de conversação além das fronteiras. O substrato das relações entre as diferentes áreas protegidas pode variar de um reconhecimento formal e legal das APTF dos estados envolvidos até um arranjo mais simples e embasado numa cooperação e uma distribuição das informações ${ }^{29}$. Entre as diferentes abordagens de criação e gestão das APTF, as mais frequentes envolvem situações entre duas ou mais áreas protegidas contíguas que se juntam acima de uma fronteira internacional. Podemos observar também alguns projetos mais ambiciosos, como as APTF que agregam um grupo de áreas protegidas e novos territórios partes a um processo de proteção. Esses projetos buscam uma maior proteção que as clássicas áreas protegidas, incorporado no ordenamento de APTF em corredores e zona-tampão, permitindo uma melhor conectividade de funções entre as áreas protegidas ${ }^{30}$. Assim, o Banco Mundial já participou de projetos de unificação de quatro áreas protegidas não adjacentes nas montanhas do Tien Shan na Ásia central, que são cercadas de terras podendo ser inclusas em $\mathrm{APTF}^{31}$. Em alguns casos, a implementação de APTF pode estender-se até um grupo de áreas protegidas isoladas não conectadas que dividem uma realidade ecológica e problemas semelhantes. Assim, por exemplo, na região dos grandes lagos da África, uma iniciativa de APTF foi implementada, associando o parque nacional da Kibira no Burundi, o parque nacional de

de Sherbrooke, Canada, 2013.

28 SANDWITH, T. Transboundary Protected Area for Peace. and Co-operation. World Comission on Protected Áreas. Best Practice Protected Area Guidelines Series, n. 7, p. 3, 2001. Disponível em: $<$ https://cmsdata.iucn.org/downloads/pag_007.pdf $>$. Acesso em 12 abr. 2016.

29 MONTPETIT, Sandrine. Les aires protégées transfrontalières: au-delà de la conservation de la biodiversité. 2013. 101f. Essai de maîtrise en écologie internationale. Faculté des Sciences, Université de Sherbrooke, Canada, 2013.

30 MONTPETIT, Sandrine. Les aires protégées transfrontalières: au-delà de la conservation de la biodiversité. 2013. 101f. Essai de maitrise en écologie internationale. Faculté des Sciences, Université de Sherbrooke, Canada, 2013.

31 DUDLEY, N. A typology of transboundary protected areas: different approaches for different needs. Paper for IUCN, drawing on results of an ITTO/IUCN workshop: IUCN/ UNEP-WCPA, 2007.
Virunga em República Democrática do Congo (RDC) e o parque nacional dos Vulcões da Rwanda. Todos têm por objetivos uma gestão comum frente a problemas de controle de terras agrícolas ${ }^{32}$. Finalmente, em algumas situações, a necessidade ou a vontade de implementar uma ATPF não foi conseguida pela negociação entre dois países, mas o ordenamento do território dentro de um país pode contribuir para medidas de conservação do país vizinho. Por exemplo, na ilha de Borrneu, a melhora da gestão das florestas do lado da fronteira malasiana contribui para preservar as populações da grande fauna do lado indonésio, no parque Kayan Mentarang ${ }^{33}$.

A APTF pode ser administrada e gerenciada em cooperação com um grupo de instituições responsáveis de ambos os lados da fronteira ou pela criação de um órgão internacional independente respondendo as diferentes autoridades envolvidas, tais como os governos nacionais, investidores privados, e ONG's. A criação de tal órgão facilita o estabelecimento de um plano de ordenamento conjunto dos parques internacionais, assim recomenda a IUCN ${ }^{34}$. A estrutura de coordenação implementada para a gestão da APTF tem a vantagem de ser representativa dos diferentes atores envolvidos. Ela responde aos interesses dos grupos participantes do projeto tais como científicos, comunidades locais, autoridades locais, as ONG's locais, assim como as empresas privadas. No entanto, algumas vozes nos advertem sobre os riscos de tal abordagem. Com efeito, ainda que uma área protegida transfronteiriça possa apresentar as mesmas caraterísticas ecológicas, não significa necessariamente que isso seja o mesmo no que tange as características sociais, econômicas e políticas. A gestão conjunta do ecossistema ou da APTF deve, então, se estabelecer progressivamente pela implementação de medidas comuns de gestão entre as instituições presentes. Dessa maneira, a integração institucional poderá apresentar um melhor grau de adequação às diferentes

32 DUDLEY, N. A typology of transboundary protected areas: different approaches for different needs. Paper for IUCN, drawing on results of an ITTO/IUCN workshop: IUCN/ UNEP-WCPA, 2007.

33 DUDLEY, N. A typology of transboundary protected areas: different approaches for different needs. Paper for IUCN, drawing on results of an ITTO/IUCN workshop: IUCN/ UNEP-WCPA, 2007.

34 MEDINA, Lucile. L'Amitié et la Fraternité par-delà les frontières. Coopérations binationale et trinationale entre parcs nationaux des États d'Amérique centrale. In: HERITIER, Stéphane; LASLAZ, Lionel (Org.). Les parcs nationaux dans le monde: protection, gestion et développement durable. Paris: Ellipses, 2008. p. 145-164. 
situações práticas ${ }^{35}$. É frequente observar uma pluralidade de instituições que atuam e intervêm na gestão de áreas protegidas, ainda mais quando se trata de áreas transfronteiriças. A coordenação entre essa variedade de instituições, às vezes muito recentes e com pouco experiência em assuntos internacionais, pode se tornar uma empreitada complexa e árdua ${ }^{36}$. A gestão de uma área protegida nacional já constitui um desafio de gestão para as diferentes demandas de aprovações necessárias num país determinado. Consequentemente, a carga burocrática é multiplicada e ampliada pela complexidade do sistema decisional no caso das APTF e obviamente a curto termo a implementação de uma área transfronteiriça não simplifica a gestão ${ }^{37}$.

Em virtude dessa série de desafios, a instauração de um clima de cooperação entre os participantes é claramente benéfico e essencial à implementação de uma $\mathrm{APTF}^{38}$. A literatura disponível sobre o assunto tem apresentado inúmeras vantagens a favor da cooperação entre atores e especificamente entre estados. A cooperação transfronteiriça permitiria um melhor domínio dos diferentes problemas relativos a fronteiras tais como exploração ilegal de madeira, incêndios, caças ilegais, poluição e contrabanda. Oferece também a possibilidade de enfrentar um dos maiores problemas das regiões fronteiriças, que é a gestão comum dos recursos hídricos, que frequentemente representa uma discordância profunda entre os estados, tendo em vista a sua possível raridade ${ }^{39}$. Ademais, ela facilitaria a troca de informações para as administrações alfandegárias e de imigração ${ }^{40}$. Por outro lado, a criação de uma APTF aumenta

35 BONNIN, Marie. Les corridors écologiques: vers un troisième temps du droit de la conservation de la nature? Paris: L'Harmattan, 2008.

36 BONNIN, Marie. Les corridors écologiques: vers un troisième temps du droit de la conservation de la nature ? Paris: L'Harmattan, 2008.

37 MONTPETIT, Sandrine. Les aires protégées transfrontalières: au-delà de la conservation de la biodiversité. 2013. 101f. Essai de maîtrise en écologie internationale. Faculté des Sciences, Université de Sherbrooke, Canada, 2013.

38 VASILIJEVIC, M. et al. Transboundary Conservation: A systematic and integrated approach. 2015. Disponível em: <https://portals.iucn. org/library/efiles/documents/PAG-023.pdf>. Acesso em: 14 mar. 2016.

39 MEDINA, Lucile. L'Amitié et la Fraternité par-delà les frontières. Coopérations binationale et trinationale entre parcs nationaux des États d'Amérique centrale. In: HERITIER, Stéphane; LASLAZ, Lionel (Org.). Les parcs nationaux dans le monde: protection, gestion et développement durable. Paris: Ellipses, 2008. p. 145-164.

40 SANDWITH, T. Transboundary Protected Area for Peace. and Co-operation. World Comission on Protected Áreas. Best Prac- a credibilidade para um possível tombamento de um sítio como patrimônio internacional da UNESCO. Os esforços comuns permitiriam uma coordenação melhor das lutas contra os danos ambientais, assim como as mudanças climáticas, as chuvas ácidas e a contaminação do solo $^{41}$. O encorajamento a boas práticas ecológicas para o vizinho pode ser visto igualmente como uma possibilidade para os países de estimularem-se, mutualmente, com finalidade de implementar outras medidas de conservação, indo até a criação de outras APTF nas fronteiras ${ }^{42}$.

Outros argumentos recenseados a favor da cooperação são aqueles de natureza econômica. A implementação das ATPF poderia alavancar uma série de considerações econômicas em nível de desenvolvimento, de financiamento da cooperação, de turismo, de geração de empregos, assim como de desenvolvimento sustentável. Pois, tratando-se, de certa forma de abertura de fronteiras, a possibilidade de trocas comerciais bilateral ou plurilateral beneficia-se quase, automaticamente, dessa abertura e permitiria atrair investidores ${ }^{43}$.

\subsection{Um objetivo de paz?}

Bem que as APTF tenham sido lançadas para cumprir um objetivo de conservação, elas acabam favorecendo as relações internacionais. Essa oportunidade pode até mesmo constituir o objetivo principal quando se trata dos parques da paz. Esses parques são considerados como elementos de reestabelecimento das relações diplomáticas entre estados, além de operar pela conservação da biodiversidade. Com a cooperação e a distribuição dos benefícios, as APTF têm o potencial de amenizar as tensões que podem existir entre estados

tice Protected Area Guidelines Series, n. 7, p. 3, 2001. Disponível em: $<$ https://cmsdata.iucn.org/downloads/pag_007.pdf >. Acesso em 12 abr. 2016.

41 SANDWITH, T. Transboundary Protected Area for Peace. and Co-operation. World Comission on Protected Áreas. Best Practice Protected Area Guidelines Series, n. 7, p. 3, 2001. Disponível em: $<$ https://cmsdata.iucn.org/downloads/pag_007.pdf >. Acesso em 12 abr. 2016.

42 MONTPETIT, Sandrine. Les aires protégées transfrontalières: au-delà de la conservation de la biodiversité. 2013. 101f. Essai de maitrise en écologie internationale. Faculté des Sciences, Université de Sherbrooke, Canada, 2013.

43 MACKINNON, Kathy. Transboundary reserves - World Bank implementation of the ecosystem approach. Washington, DC: World Bank, 2000. Disponível em: < http://documents.worldbank.org/curated/ en/2000/04/693166/transboundary-reserves-world-bank-implementation-ecosystem-approach>. Acesso em: 15 abr. 2016. 
ou entre comunidades locais fronteiriças. O conceito de parque transfronteiriço opõe-se, de certa forma, à concepção tradicional da fronteira como elemento simbólico de guerra, de segregação e de controle territorial para poder transformá-la em elemento de abertura e de trocas $^{44}$.

A categoria de parque pela paz busca cumprir diversas funções, como favorecer a comunicação entre os participantes por meio de interesses comuns e reforçar os laços de amizade, estabelecendo um início de confiança entre os ex-beligerantes. A categoria participa supostamente da integração das comunidades locais que foram afastadas da gestão. A marginalização das populações indígenas fronteiriças favorece as atividades criminosas transfronteiriças. O fato de reunir populações antigamente divididas, assim como de considerá-las como parceiras, faz parte dos requisitos da gestão das APTF, para reduzir as tensões.

Além das diversas funções que um parque da paz possa cumprir, um de seus papeis mais comuns consiste em servir de área tampão entre dois estados em conflito. Nesse caso, o parque da paz ocupa uma região pós-conflito "esvaziada" em partes territoriais de fronteiras. A eficácia dos parques da paz em amenizar as tensões e manter a paz é sempre uma tarefa de difícil avaliação. No entanto, uma análise estatística feita num número representativo de zona tampão no mundo deixa pensar que quando são totalmente desmilitarizadas e se forem de no mínimo $2 \mathrm{~km}$ de largura, essas áreas permitem reduzir o risco de conflitos armados em $90 \%$. O resultado do estudo somente envolveu, como já mencionado, tipos de zona-tampão esvaziadas, consequentemente, ela não informa de forma categórica sobre uma zona tampão ocupada por uma APTF. O risco contrário relacionado à implementação de uma APTF não deve ser descartado, com efeito, a probabilidade de uma consequência contrária é sempre possível. A nova área possa ser fomentadora de litígio ou conflitos, notadamente se o território for provido em recursos naturais. A abertura das fronteiras, como já mencionado, não garante totalmente a ausência de tráfico e de atividades criminosas.

44 MONTPETIT, Sandrine. Les aires protégées transfrontalières: au-delà de la conservation de la biodiversité. 2013. 101f. Essai de maîtrise en écologie internationale. Faculté des Sciences, Université de Sherbrooke, Canada, 2013.

45 LEJANO, R. (2006). Apud MONTPETIT, Sandrine. Les aires protégées transfrontalières: au-delà de la conservation de la biodiversité. 2013. 101f. Essai de maitrise en écologie internationale. Faculté des Sciences, Université de Sherbrooke, Canada, 2013.
Daí a importância de integração das comunidades locais fronteiriças na gestão e na distribuição dos benefícios. Um questionamento pertinente foi formulado quanto ao papel dos parques da paz: a promoção da paz é a consequência da ideia de proteção da natureza ou, pelo contrário, seria a pacificação das relações internacionais que permitiria melhor impor uma ideologia ecologista $^{46}$ ? (Depraz, 2008)?

A observação da implementação de uma área protegida na África austral gerou algumas análises pertinentes e de grande interesse, especificamente na literatura anglo saxã $\tilde{a}^{47}$. O Great Limpopo Transfrontier Park (GLTP) é um Parque da Paz que reúne o Parque Nacional Kruger da África do Sul, o Parque Nacional do Limpopo em Moçambique e o Parque Nacional do Gonarezhou em Zimbábue. O acordo trilateral foi assinado em novembro de 2000 e a abertura do parque transfronteiriça foi iniciada em 2004. Trata-se de um parque excepcional em relação a sua riqueza ecológica, tendo uma superfície de $35000 \mathrm{~km} 2$ de parques inseridos numa área de conservação de quase 100000 km2 divido nos territórios de 3 países. Outro fato a ser destacado é que a área transfronteiriça foi, durante muito tempo, o palco de intensas zonas de combates e de conflitos armados. Moçambique e o Zimbábue assumiram um papel de destaque na linha de frente contra o apartheid ${ }^{48}$. Assim, o GLTP responde, perfeitamente, à definição dos parques da paz dada pela UICN, pois é um subconjunto particular de áreas protegidas no qual há um objetivo claro de proteção da biodiversidade, uma cooperação entre pelo menos dois estados ou entidades subnacionais, assim como um objetivo claro de $\mathrm{paz}^{49}$. Esse parque é oficialmente dedicado à proteção e conservação da diversidade biológica, dos recursos naturais e culturais, assim como da promoção e cooperação pela paz. Trata-se de uma paz lato sensu, ou

46 DEPRAZ (2008) Apud MONTPETIT, Sandrine. Les aires protégées transfrontalières: au-delà de la conservation de la biodiversité. 2013. 101f. Essai de maîtrise en écologie internationale. Faculté des Sciences, Université de Sherbrooke, Canada, 2013.

47 DUFFY Rosaleen. Peace parks and global politics: the paradoxes and challenges of global Governance. In: SALEEM A. H. (Org.). Peace Parks. Conservation and Conflict Resolution. Cambridge: The MIT Press, Massachusetts (USA) and London (U.K.), 2007.

48 BELAIDI, Nadia. Le Great Limpopo Transfrontier Park. Echo Géo, v. 7, 2008.

49 SANDWITH, T. Transboundary Protected Area for Peace. and Co-operation. World Comission on Protected Áreas. Best Practice Protected Area Guidelines Series, n. 7, p. 3, 2001. Disponível em: $<$ https://cmsdata.iucn.org/downloads/pag_007.pdf $>$. Acesso em 12 abr. 2016. 
seja, não se trata, exclusivamente, da paz no sentido do registro militar, mas sim, de um clima pacífico em torno de assuntos sociais, econômicos e culturais. A lógica de implementação do parque embasa-se sobre a ideia que a articulação das áreas de conservação facilita a resolução de conflitos territoriais, transformando as preocupações ambientais em objeto de cooperação entre soberanias políticas $^{50}$.

Se as áreas protegidas pretendem ser uma ferramenta importante de proteção e de manutenção da biodiversidade em estratégias de conservações globais, seu objetivo ecológico não é neutro, nem socialmente e nem politicamente. As diferentes funções políticas das áreas protegidas participam de uma construção social, cultural e econômica. Assim, em países em desenvolvimento, a pobreza, as desigualdades sociais, a corrupção, as tensões étnicas e os rastros de um passado colonial podem favorecer situações pelas quais as APTF agem como instrumentos de controle dos recursos. O conceito de parque da paz enfrenta um verdadeiro desafio para se ater a seus objetivos e não se deixar instrumentalizar ${ }^{51}$. O contexto jurídico que poderia sustentar um objetivo de paz social, econômica e cultural é fragmentado e de uma certa complexidade, como já foi mencionado no tópico 1.2 (Uma profusão de atores e uma heterogeneidade normativa)- É justamente a situação jurídica do GLTP. Essas articulações de categorias e de superposições de normas não são desprovidas de efeitos jurídicos e políticos. Assim, o GLTP deu primazia ao potencial turístico em detrimento da manutenção das populações locais. Assim, longe de uma posição supostamente federativa e promovedora do desenvolvimento das comunidades locais, essas foram desalojadas sem discussão ou negociação. O papel do Banco Mundial que participou do financiamento do parque parece ter ignorado o seu impacto na vida das populações locais preferindo favorecer o desenvolvimento do ecoturismo apresentado como um elemento do desenvolvimento sustentável ${ }^{52}$. Parece ser paradoxal incitar o fomento de um economia sustentável sem a participação do seus atores mais pertinentes. A articulação das áreas de conservação operada

50 BELAIDI, Nadia. Le Great Limpopo Transfrontier Park. Echo Géo, v. 7, 2008.

51 BELAIDI, Nadia. Le Great Limpopo Transfrontier Park. Echo Géo, v. 7, 2008.

52 DUFFY Rosaleen. Peace parks and global politics: the paradoxes and challenges of global Governance. In: SALEEM A. H. (Org.). Peace Parks. Conservation and Conflict Resolution. Cambridge: The MIT Press, Massachusetts (USA) and London (U.K.), 2007. dentro do projeto de implementação do GLTP foi apresentada como um meio de facilitação da resolução de conflitos territoriais partir do incentivo ao diálogo em torno de interesses comuns. No entanto, esses conflitos estão inseridos dentro de estruturas sociais, e culturais, assim, qualquer mudança formal ou organizacional provocará inevitavelmente uma mudança de conteúdo e de substância. Uma recomposição territorial que tem por objeto transformar as preocupações ambientais em temas de cooperação entre diversas estruturas jurídicas e políticas deve considerar o meio ambiente em função do que ele é e não só para uma representação ${ }^{53}$. Como afirmar a prevalência do aspecto turístico e de alguns serviços ambientais vitais se a garantia de permanência de populações locais não for considerada?

Assim, uma certa análise do GLTP mostra que sua implementação favoreceu uma política de agências de fomento internacionais e desconsiderou a garantia e o respeito de outros elementos. Essa postura tende a considerar a abertura das fronteiras, não como um fator de desenvolvimento comum, mas sim como uma preocupação de lutas internas ao campo da biodiversidade em termos de dominação político com um substrato econômico.

Geopoliticamente stricto sensu, o parque do Great Limpopo traduz a abertura do território sul-africano em relação aos vizinhos a partir de uma transformação das fronteiras. A nova organização regional desse território concebida a partir de um projeto transfronteiriça e transnacional leva a África do sul a se erguer em verdadeira potência internacional, não só na África austral, mas sim, em nível de liderança no desenvolvimento africano. Isso favorece, no plano mundial, sua identificação como uma das principais vozes do sul ${ }^{54}$.

A proteção da biodiversidade passa por uma fase "green-grabbing" com a intervenção de atores privados. Um processo de privatização ocorre no gerenciamento de alguns parques nacionais. Assim, por exemplo, o parque nacional Kruger, começou a terceirizar a gestão financeira das atividades para empresas internacionais com o apoio técnico do Banco Mundial em plena contradição com os objetivos, teoricamente, proclamados

53 BELAIDI, Nadia. Le Great Limpopo Transfrontier Park. Echo Géo, v. 7, 2008.

54 DUFFY Rosaleen. Peace parks and global politics: the paradoxes and challenges of global Governance. In: SALEEM A. H. (Org.). Peace Parks. Conservation and Conflict Resolution. Cambridge: The MIT Press, Massachusetts (USA) and London (U.K.), 2007. 
de recomposição territorial ${ }^{55}$.

O fenômeno já chamou a atenção de algumas ONG's, como a Forest People, que já em 2003 alertava num relatório que, em regra geral, as áreas protegidas continuam sendo implementadas e gerenciadas sem o respeito dos direito das populações autóctones ${ }^{56}$.

\section{Considerações finais}

Raras são as pesquisas que tomam por objeto as áreas protegidas transfronteiriças, suas condições jurídicas e suas implicações geopolíticas. Quisemos demonstrar a irredutibilidade do regime jurídico das áreas, sejam elas parques da paz, reservas da biosfera da Unesco ou do Conselho da Europa, áreas úmidas da convenção Ramsar, e tantas outras categorias, a uma simples questão jurídica que seria neutra, objetiva e desprovida de caráter politico. Antes de tudo, as áreas protegidas são fruto de decisões politicas, produtos de soberania unilateral ou plurilateral, necessitando o suporte do direito internacional, seja jus dispositivum (por meio de convenções internacionais gerais ou regionais), seja um fenômeno de soft law.

Uma das razões, pouca evocada, do desenvolvimento das APTF pode ser relacionada aos estudos produzidos na década de 80 pelo Interagency Task Force criada pelo Congresso dos EUA, que elaborou uma estratégia da conservação da diversidade biológica ${ }^{57}$. Um vasto programa legislativo e regulamentar foi lançado nos meados dos anos para amenizar a exposição da fragilidade do sementes da agricultura norte americana. Foram reestruturadas as redes de conservação ex-situ. Houve, sobretudo, incentivos e apoios dados a criação de redes mundiais de áreas protegidas, especificamente em países em desenvolvimento de regiões tropicais e subsídios reforçados para as organizações internacionais não governamentais que atuam na conservação da

55 BELAIDI, Nadia. Le Great Limpopo Transfrontier Park. Echo Géo, v. 7, 2008.

56 Forest People's Program 2007. Apud GESLIN, Albane. Aires protégées transfrontalières et parcs pour la paix : entre géopolitique des conflits et protection transnationale de la diversité bio-culturelle. In: AILINCA Mihaela; LAVOREL Sabine. (Org.). Exploitation des ressources naturelles et protection des droits de l'homme. Paris: Éd. Pedone, 2013. p. 105-120.

57 HUFTY, Marc. La gouvernance internationale de la biodiversité, Etudes internationales, v. 32, n. 1, p. 7, mars 2001. natureza. Assim, o orçamento da ajuda e da cooperação norte americana em prol ao desenvolvimento relaciona e prioriza as questões de conservação. Politicamente e de um ponto de vista das relações internacionais, o conceito de segurança nacional dos EUA alarga-se a segurança alimentar por meio da proteção a natureza e a biodiversidade. O abastecimento genético e sua conservação são tão importantes quanto a segurança militar ou energética. Essa hipótese representou o arcabouço da evolução das APTF, cujo debate em torno da alternativa conservação/preservação adquiriu uma dimensão eminentemente mais política do que parecia inicialmente. Não se trata, apenas, de discorrer sobre os benefícios de uma pura e rígida proteção de caráter preservacionista opostos a uma conservação mais antropocêntrico, mas sim de poder perceber as linhas de ruptura ou de mudança de paradigmas. O campo social da biodiversidade, no sentido dos conceitos forjado pelo sociólogo Pierre Bourdieu, passou por muitas evoluções nos últimos 50 anos. Dentro dos possíveis discursos que revelam um marco teórico e regulador adotados pelos atores do campo, podemos mencionar, além do discurso conservacionista/preservacionista, a criação dos discursos desenvolvimentista, agrícola, econômico e culturalista ${ }^{58}$. A mudança de eixo político-ideológico da concepção das APTF, até então atravessada pela alternativa conservacionismo/preservacionismo, esboça, mas de forma nítida, um movimento para uma visão de preservação de paz, supostamente desinteressada da questão da conservação in situ, que não podemos esquecer, é ideal para a questão dos recursos genéticos agrícolas em termos de segurança alimentar de países do norte. Assim, o campo da biodiversidade continua de forma intensa sua estruturação e o trabalho mostrou a multidão de atores que se agregam em torno do tema desde que a biodiversidade emergiu na pauta das agendas de várias organizações internacionais, sejam de natureza governamental ou não. Nossa abordagem, feita a partir dos conceitos de campo, habitus e capitais simbólicos, pretende ter contribuído a desvelar o caráter eminentemente político de tais empreendimentos, mas também os interesses e os aspectos de dominação em termos geopolíticos.

Não pretendemos ter esgotado a questão, pelo contrário, já que a matéria é tão rica e densa. Sem dúvida alguma, outros vieses metodológicos são possíveis

58 BRAHI, Nicolas; LOUAFI, Sélim. La convention sur la diversité biologique à la croisée de quatre discours. Les Rapports de l'IDDRI, n. 3, p. 32, 2004 
e disponíveis notadamente em termos de uma análise geográfica do direito ${ }^{59}$ mais específica que a nossa, que apesar de ter abordado a problemática a partir do conceito geográfico de território, enfatizou mais os aspectos geopolíticos, o que reforça a pertinência e a vitalidade de uma abordagem zetética da biodiversidade ${ }^{60}$.

\section{REFERÊNCIAS BIBLIOGRÁFICAS}

BASILIEN-GAINCHE, Marie-Laure. Les interactions entre normes et territoires: l'Europe et le développement durable. In: ZARKA, Yves-Charles (Org.). Le monde émergent - Lieux. Paris: Armand Colin, 2010. p. 243-263.

BASSET, Thomas J.; GAUTIER Denis. Territorialisation et pouvoir : la Political Ecology des territoires de conservation et de développement. Echo Géo, v. 29, 2014.

BELAIDI, Nadia. Le Great Limpopo Transfrontier Park. Echo Géo, v. 7, 2008.

BONNIN, Marie. Les corridors écologiques: vers un troisième temps du droit de la conservation de la nature ? Paris: L'Harmattan, 2008.

BOTTI Dominique. La biodiversité comme champ de lutte: La Convention sur la diversité biologique et la réglementation international. Genève: Mémoire de DES, IUED, 1997.

BOURDIEU, Pierre. Questions de sociologie. Paris : Les Éditions de Minuit, 1984.

BOURDIEU, Pierre. Raisons pratiques. Sur la théorie de l'action. Paris: Points Essais, 1996.

BRAHI, Nicolas; LOUAFI, Sélim. La convention sur la

59 Para entender e descobrir o movimento de análise geográfica do direito consultar a obra coletiva FOREST, Patrick. Géographie du droit. Épistémologie, développement et perspectives. Québec: Presses de l'Université Laval, coll. Dikè, 2009. E para uma ilustração europeia aplicada ao desenvolvimento sustentável: BASILIEN-GAINCHE, Marie-Laure. Les interactions entre normes et territoires: l'Europe et le développement durable. In: ZARKA, Yves-Charles (Org.). Le monde émergent - Lieux. Paris: Armand Colin, 2010. p. 243-263. Para a relação entre biodiversidade e territórios, consultar: FRANCHOMME, Magalie; BONNIN, Marie ; HINNEWINKEL, Christelle. La biodiversité " aménage-t-elle » les territoires? Vers une écologisation des territoires. Développement durable et territoires, v. 4, n. 1, avril 2013.

60 Referindo-se a terminologia empregada por Tércio Sampaio. diversité biologique à la croisée de quatre discours. Les Rapports de l'IDDRI, n. 3, p. 32, 2004.

BRODHAG, Christian. Quelle gouvernance internationale du développement durable. In: PENNEQUIN, Gilles; MOCILNIKAR, Antoine-Tristan (Org.). L'Atlas du développement durable. Paris: d'Organisation. Eyrolles, 2011. p. 199.

CHÉROT, Jean-Yves ; FRYDMAN, Benoît (Org.). La science $d u$ droit dans la globalisation. Bruxelles: Bruylant, coll. « Penser le droit », 2012.

DUDLEY, N. A typology of transboundary protected areas: different approaches for different needs. Paper for IUCN, drawing on results of an ITTO/IUCN workshop: IUCN/ UNEP-WCPA, 2007.

DUDLEY, Nigel. Lignes directrices pour l'application des catégories de gestion aux aires protégées. 2008. Disponível em: $<$ https://portals.iucn.org/library/efiles/edocs/PAPS016-Fr.pdf>. Acesso em: 24 mar. 2016.

DUFFY Rosaleen. Peace parks and global politics: the paradoxes and challenges of global Governance. In: SALEEM A. H. (Org.). Peace Parks. Conservation and Conflict Resolution. Cambridge: The MIT Press, Massachusetts (USA) and London (U.K.), 2007.

FOREST, Patrick. Géographie du droit. Épistémologie, développement et perspectives. Québec: Presses de l’Université Laval, coll. Dikè, 2009.

FRANCHOMME, Magalie; BONNIN, Marie ; HINNEWINKEL, Christelle. La biodiversité « aménage-t-elle » les territoires? Vers une écologisation des territoires. Développement durable et territoires, v. 4, n. 1, avril 2013.

GESLIN, Albane. Aires protégées transfrontalières et parcs pour la paix : entre géopolitique des conflits et protection transnationale de la diversité bio-culturelle. In: AILINCA Mihaela; LAVOREL Sabine. (Org.). Exploitation des ressources naturelles et protection des droits de l'bomme. Paris: Éd. Pedone, 2013. p. 105-120.

GUYOT, Sylvain. Géopolitique des parcs (trans) frontaliers en Afrique Australe. Les Cahiers d'Outre-Mer, v. 234, avril-juin 2006.

HUFTY, Marc. La gouvernance internationale de la biodiversité, Etudes internationales, v. 32, n. 1, p. 5-29, mars 2001.

KROPF, Marcela Stuker; OLIVEIRA, Rogério Ribeiro. Áreas protegidas fronteiriças. Revista Perspectiva Geográfi- 
ca, Unioeste, v. 8, n. 9, 2013.

LAHIRE, Bernard. La nature du cognitif en questions. In: LAHIRE, Bernard; ROSENTAL, Claude (Org.). La cognition au prisme des sciences sociales. Paris: Editions des archives contemporaines, 2008. p. 55-106.

MAB FRANCE. Le MAB de l'UNESCO. Disponível em: <http://www.mab-france.org/fr/mab-france/>. Acesso em 10 abr. 2016.

MACKINNON, Kathy. Transboundary reserves - World Bank implementation of the ecosystem approach. Washington, DC: World Bank, 2000. Disponível em: <http://documents.worldbank.org/curated/en/2000/04/693166/ transboundary-reserves-world-bank-implementation-ecosystem-approach>. Acesso em: 15 abr. 2016.

MEDINA, Lucile. L'Amitié et la Fraternité par-delà les frontières. Coopérations binationale et trinationale entre parcs nationaux des États d'Amérique centrale. In: HERITIER, Stéphane; LASLAZ, Lionel (Org.). Les parcs nationaux dans le monde: protection, gestion et développement durable. Paris: Ellipses, 2008. p. 145-164.

MONTPETIT, Sandrine. Les airesprotégées transfrontalières: au-delà de la conservation de la biodiversité. 2013. $101 \mathrm{f}$. Essai de maittrise en écologie internationale. Faculté des Sciences, Université de Sherbrooke, Canada, 2013.

OLIVIER, Juliette. Les nouveaux acteurs du droit de l'environnement. Le rôle de l'UICN dans l'élaboration du droit de l'environnement. Revue Européenne de Droit de l'Environnement, n. 3, p. 274-296, 2005.

SANDWITH, T. Transboundary Protected Area for Peace. and Co-operation. World Comission on Protected Áreas. Best Practice Protected Area Guidelines Series, n. 7, p. 3, 2001. Disponível em: <https://cmsdata.iucn.org/ downloads/pag_007.pdf>. Acesso em 12 abr. 2016.

SOUZA, João Victor Campos de. Congressos Mundiais de Parques Nacionais da UICN (1962-2003): registros e reflexões sobre o surgimento de um novo paradigma para a conservação da natureza. 2013. 225 f. Dissertação (Mestrado) - Programa de Pós-Graduação em Desenvolvimento Sustentável, Universidade de Brasília, Brasília, 2013.

STEIMAN, Rebeca. Áreas protegidas em zona de fronteira. Para Onde!?, v. 5, p. 101-121, ago.-dez. 2011. (Especial)

UNIÃO INTERNACIONAL PARA CONSERVAÇÃO DA NATUREZA. L'Histoire. 2014. Disponível em: <http://cmsdata.iucn.org/downloads/fre_who_ we_are_iucn_congress_history.pdf $>$. Acesso em: 3 abr. 2016.

VASILIJEVIC, M. Et al. Transboundary Conservation: $A$ systematic and integrated approach. 2015. Disponível em: $<$ https://portals.iucn.org/library/efiles/documents/ PAG-023.pdf>. Acesso em: 14 mar. 2016. 
Para publicar na Revista de Direito Internacional, acesse o endereço eletrônico www.rdi.uniceub.br ou www.brazilianjournal.org.

Observe as normas de publicação, para facilitar e agilizar o trabalho de edição. 